\title{
PHYSICO-CHEMICAL AN D TECHNOLOGICAL REGULARITIES OF FOAM POLYSTYRENE DEGAZATION IN THE LIQUID MEDIUM
}

\author{
Volodymyr M oravskyi ${ }^{1, *}$, Volodymyr Levytskyi ${ }^{1,2}$, M ykhailo Bratychak, Jr. ${ }^{1}$, \\ Ulyana Khromyak ${ }^{3}$, Marta Kuznetsova ${ }^{1}$, Nataliia Chopyk ${ }^{1}$
}

https://doi.org/10.23939/chcht13.03.347

\begin{abstract}
The regularities of compaction process of foam polystyrene plastics in the liquid mediums have been discovered. The influence of medium nature, temperature and technological characteristics of foam polystyrene (imaginary density, shredding degree) on the kinetics of gas phase release in the conditions of polystyrene segmental mobility has been determined. The design and method of calculation of the reactor for the process of foam polystyrene degazation via the continuous scheme is offered.
\end{abstract}

Keywords: foam polystyrene, butanol, degazation, recycling, secondary use.

\section{Introduction}

Owing to the combination of high working properties with the processability by all methods known for polymers, the polystyrene is widely used in the production of goods of various applications, including the foamed ones. Foam polystyrene is being applied in modern construction, in buildings insulation systems $[1$, 2], as well as in thermal insulation of capacitive machines and pipelines. The combination of high hygienic indicators [3] and heat-insulating properties of foam polystyrene makes it an ideal material for packaging and storage of food products. Another field of foamed polystyrene application, in which it practically does not have competitors, is the packaging of consumer electronics products $[4,5]$. Such wide application of foam polystyrene in various industries causes the availability of a large amount of wastes. The above-mentioned wastes are mainly agglomerated in the form of utilized packaging and industrial waste.

\footnotetext{
${ }^{1}$ Lviv Polytechnic National University,

12, S.Bandery St., 79013 Lviv, Ukraine

${ }^{2}$ The John Paul II Catholic University of Lublin,

14, Al. Racławickie, 20-950 Lublin, Poland

${ }^{3}$ Lviv State University of Life Safety,

35, Kleparivska St., 79000 Lviv, Ukraine

vmoravsky@gmail.com

(C) Moravskyi V., Levytskyi V., Bratychak M. Jr, Khromyak U., Kuznetsova M., Chopyk N., 2019
}

Secondary processing of foamed polymers by the traditional methods [6], such as injection molding and extrusion requires elevated attention through the presence of gas inclusions, which during the melting of polymer materials adversely affect the melt homogeneity and, certainly, the quality of finished products with comparatively low productivity of equipment. In this regard, it is necessary to develop methods of raw materials preparation that would make it possible to minimize this negative impact. Among the methods of preparing of foamed poly-materials for recycling the most effective in economic and technological aspects are the methods based on the complete or partial removal of gas inclusions without pressure, in particular, by heating of foam plastic wastes in the air or in the liquid phase [7].

Such prepared wastes can be applied as additives to the primary polymer raw materials with the purpose of their utilization, as well as improvement and regulation of some properties of primary raw materials [8]. Furthermore, such secondary raw materials can be used to create completely new composite materials with predetermined technological properties [9-11].

The primary aim of the work was to determine the influence of medium nature on the regularities of foam polystyrene degazation and develop the design and methodology for calculating the reactor for degazation process.

\section{Experimental}

The household and industrial wastes of foam polystyrene with imaginary density of $10-60 \mathrm{~kg} / \mathrm{m}^{3}$ have been applied for the research. The gas phase release from the foam polystyrene samples was carried out in a liquid medium in a reactor equipped with mixing device in the air within a wide range of temperatures and pressures. The kinetics of degazation was studied by changing the volume of foam polystyrene samples in different mediums. The volume change $(\%)$ has been determined applying the spherical samples obtained by the grinding of waste products on a gear crusher with different diameter of holes, which provided the constant size of polystyrene 
particles (degree of grinding). The initial imaginary density of foam polystyrene was determined according to ISO 845:2006.

In order to calculate the geometric dimensions of the apparatus for conducting degazation in a liquid medium there has been used a method describing the particle sedimentation under the action of gravity force [12] applying the following similarity criteria: Archimedes (Ar), Lyashenko (Ly) and Reynolds (Re).

To determine the particle sedimentation velocity, the Archimedes criteria were calculated at first:

$$
\operatorname{Ar}=\frac{d^{3}\left(\rho-\rho_{m}\right) \rho_{m} g}{\mu_{m}{ }^{2}}
$$

where $\rho$ and $\rho_{m}$ are densities of the particle and medium, respectively, $\mathrm{kg} / \mathrm{m}^{3} ; g$ is the gravitational force equivalent, $\mathrm{m} / \mathrm{s}^{2} ; \mu_{m}$ is the dynamic viscosity coefficient of the medium, Pa s.

By the determined above described value, applying the dependences of Re and Ly criteria on the Ar criterion for the sedimentation of single particle [12], the Ly or Re criteria were defined:

$$
\mathrm{Ly}=\frac{\operatorname{Re}^{3}}{\operatorname{Ar}}=\frac{\omega_{S}{ }^{3} \rho_{m}{ }^{2}}{\mu_{m}\left(\rho-\rho_{m}\right) g}
$$

From where, the sedimentation velocity of the degassed particle was calculated by the formula:

$$
\omega_{S}=\frac{\operatorname{Re} \mu_{m}}{\rho_{m} d_{s f}}
$$

where $d_{s f}$ is the diameter of a spherical particle, $\mathrm{m}$.

Since the precipitated degassed foam polystyrene particles, as usually, have an irregular shape, instead of the $d_{s f}$ value the $d_{e}$ value of equivalent diameter of the irregular shape particle was used. It is calculated as the diameter of the conditional sphere, which volume $V$ is equal to the volume of the body of irregular shape:

$$
d_{e}=\sqrt[3]{\frac{6 V}{\pi}}=1.24 \sqrt[3]{\frac{m}{\rho}}
$$

where $m$ is the particle weight, $\mathrm{kg}$.

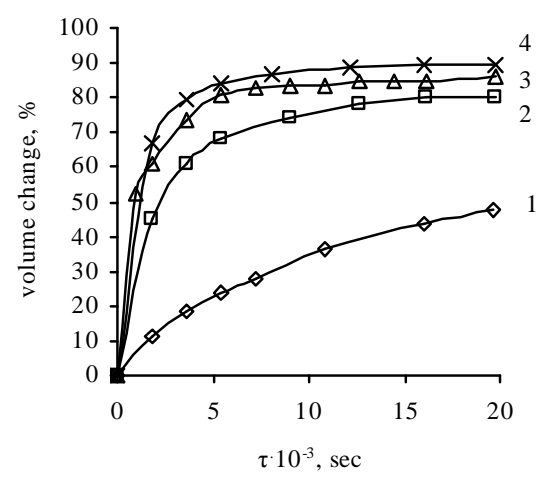

Fig. 1. Kinetics of FPS volume change in air depending on temperature, K: 343 (1); 373 (2, 4); 393 (3). Pressure, kPa: $101.3(1-3)$ and $5.33(4)$

\section{Results and Discussion}

To determine the rational parameters of compaction of foam polystyrene (FPS) the kinetic regularities of the volume change of the investigated samples at different temperatures and in different mediums were researched. It has been determined that in the case of heating FPS in the air (Fig. 1) the temperature and pressure significantly influence on the velocity of gas phase release. The temperature rise and rarefaction accelerate the velocity of gas phase release; therefrom the degazation degree is increasing. However, it should be noted that the process is quite continued (1.5-2 h) and complete release of the gas phase from the polymer cannot be achieved even at a sufficiently high temperature and rarefaction. The process of degazation stops when the content of the gas phase is $10-15 \%$. This is caused by the formation of a sufficiently dense surface crust that prevents the gas phase to be transported from the middle of the sample.

Compaction of samples in water (Fig. 2) occurs slower than in the air. That is probably due to the hydrophobic nature of the gas phase containing isopentane, which is applied for the polystyrene foaming. The above-mentioned is confirmed by a slightly higher degazation degree of FPS in aqueous solution of PVP, where the presence of surface-active polymer, in some measure, increases the affinity between gas phase and medium. Butanol, which is related to isopentane, has the highest velocity and degazation degree. It can be assumed that the compaction of foam polystyrene during heating is caused by the stress relaxation that came up in the polymer during its foaming. This process can be realized only in the case of the segmental mobility of macromolecules and occurs at the temperatures exceeding the glass transition temperature of the polymer. It should be noted that the segmental mobility of macromolecules may also occur at lower temperatures in the presence of liquid phase $[13,14]$.

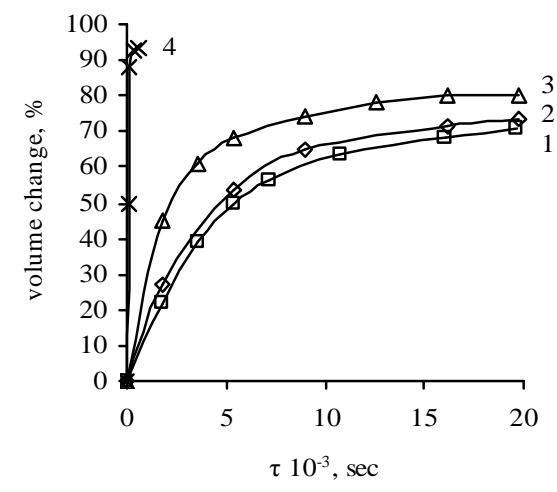

Fig. 2. Kinetics of FPS volume change at $373 \mathrm{~K}$ depending on the medium nature: water (1); 5\% aqueous solution of PVP (2); air (3); butanol (4) 
Obtained regularities of FPS degazation in different mediums can be explained by the following. In the case of degazation in air, the formation of a dense surface crust prevents the gas phase transportation from the middle of the sample. Volume reduction is primarily due to the compaction of the surface layers while the structure of the internal layers remains virtually unchanged owing to the pressure created by heated gases, which thereby counteract the relaxation of stress in the polymer. During degazation in water, the gas output even from the surface layers is impossible due to the locking of hydrophobic gas phase by water, which leads to the decrease in the degazation degree. At the same, butanol related to the isopentane fraction does not interfere with the release of the gas phase from the polymer. In addition, owing to the partial swelling of the polystyrene, the surface crust does not form, and the relaxation is accelerated. In this regard, the velocity of degazation is constant and high almost until the end of the compaction process. At the same time, the velocity and compaction degree can be regulated directly through the temperature of medium.

The researches concerning the release of the gas phase in butanol depending on the temperature have shown (Fig. 3) that the effect of temperature is displayed in increasing the velocity and degree of degazation with the temperature increasing. It should also be noted that at degazation in butanol the higher velocity and the degree of the process depth are achieved considerably more. Compared to other media, the FPS compaction process in butanol appears to be the most rational from the technological point of view. It can be explained by high productivity of the above-mentioned process and due to achievement of higher values of the density of FPS compared with the density of heated butanol the FPS compaction process in butanol can be carried out in a counter-current vertical continuous reactor.

While using butanol, the high temperature of approximately $363-383 \mathrm{~K}$ is required for the complete release of gas inclusions. One way to reduce the temperature is to apply the solvent which is more related to polystyrene. Such a solvent was blend of butanoltoluene. Thus, the temperature of the process has significantly reduced while holding high velocity and degree of degazation (Figs 4, 5). Application of toluene, which is a good solvent for polystyrene, may lead to dissolving of the latter, thus the concentration of toluene was limited up to $10 \%$. The dissolution of polystyrene at such content of toluene did not occur.

Significant intensification of the FPS compaction at increased toluene content can be explained by the greater movability of segments of polystyrene macromolecules in the presence of a good solvent for polystyrene in degassing environment. More significant segmental movability of polystyrene macromolecules with increasing temperature also leads to the increase in velocity of degazation.

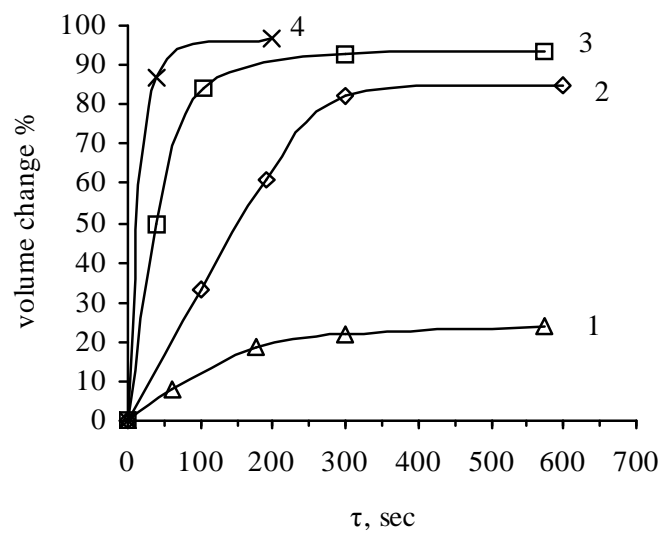

Fig. 3. Kinetics of FPS volume change in butanol depending on temperature, K: 328 (1); 343 (2); 363 (3) and $383(4)$

Since such technological characteristics of the raw material as shredding degree and the initial imaginary density of FPS can have a significant effect on the degassing process, as well as to determine the optimal technological parameters of the process, the degazation kinetics studies were conducted depending on the equivalent radius of the sample $\left(r_{e q}\right)$ and the apparent density of the FPS $\left(\rho_{i}\right)$ (Figs. 6, 7).

The time of achieving FPS maximum density is almost unchanged for samples with an equivalent radius of $(3-5) \cdot 10^{-3} \mathrm{~m}$, and at a greater radius it increases substantially and can be described by Eq. (5):

$$
\tau_{m}=11.94 r_{e q}{ }^{3}-136.32 r_{e q}{ }^{2}+509.56 r_{e q}-534.3
$$

In this manner, the optimal equivalent radius of samples after grinding for degazation is $(3-5) \cdot 10^{-3} \mathrm{~m}$. It should also be noted that such technological characteristic of FPS as the imaginary density within $10-50 \mathrm{~kg} / \mathrm{m}^{3}$ does not significantly affect the time of achievement of the maximum density, which is $90-100 \mathrm{~s}$ and can be described by the following dependence:

$$
\tau_{m}=0.0064 \rho_{i}^{2}-0.1357 \rho_{i}+90.6
$$

The studies concerning the release of gas phase from FPS were conducted and the mathematical dependencies of maximum density achievement time on equivalent radius of the samples and the initial imaginary density of FPS were defined. The aforesaid can be used to determine the rational technological parameters of the compaction process depending on the raw material characteristics, and, thus, to obtain a secondary degassed FPS of a given degree of compaction which can be applied for further recycling. 


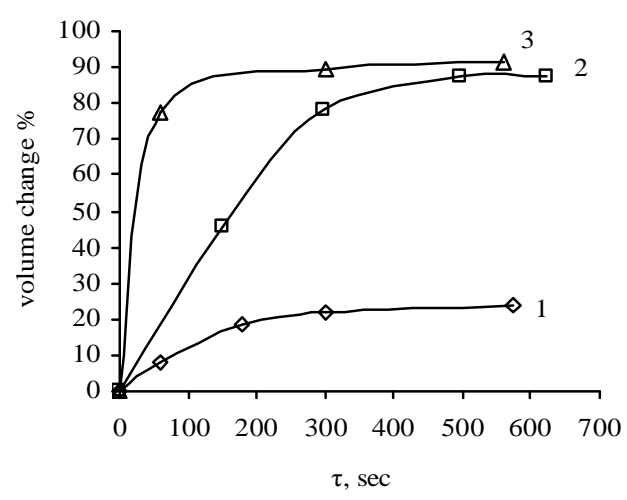

Fig. 4. Kinetics of FPS volume change at $333 \mathrm{~K}$ depending on the solvent nature: butanol (1); butanol 95\% + toluene 5\% (2) and butanol $90 \%$ + toluene $10 \%$ (3)

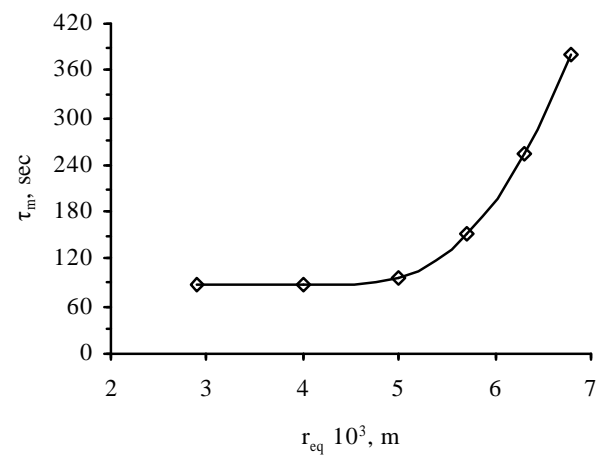

Fig. 6. Effect of equivalent radius of the sample on time of achieving FPS maximum density $\left(\tau_{m}\right)$ in butanol at $363 \mathrm{~K}$

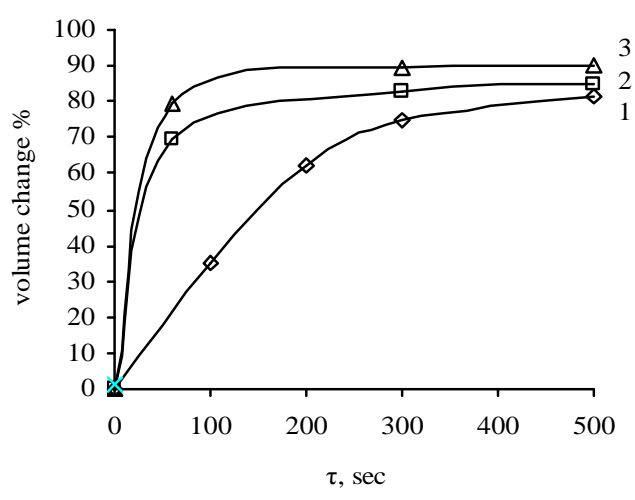

Fig. 5. Kinetics of FPS volume change in the solvent (butanol $90 \%$ + toluene $10 \%$ ) depending on temperature, K: 313 (1); $323(2)$ and 333 (3)

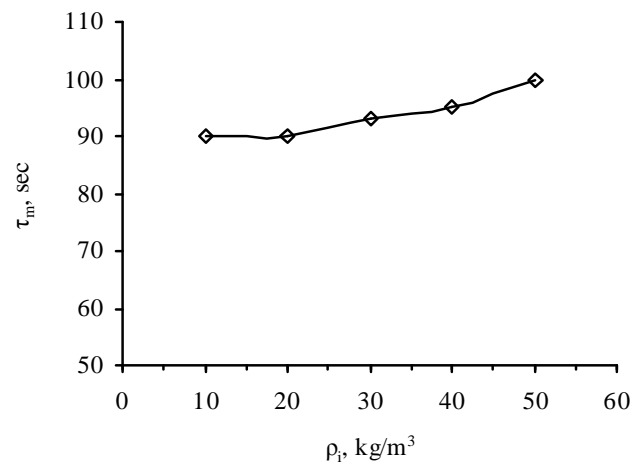

Fig. 7. Influence of apparent density of the sample on time of achieving FPS maximum density in butanol at $363 \mathrm{~K}$

Influence of medium and temperature on foam polystyrene degazation

\begin{tabular}{|c|c|c|c|c|c|}
\hline \multicolumn{3}{|c|}{ Technological parameters } & \multicolumn{2}{c|}{ Properties of FPS } \\
\hline Medium & $P, \mathrm{MPa}$ & $T, \mathrm{~K}$ & $\tau, \mathrm{min}$ & $\rho, \mathrm{kg} / \mathrm{m}^{3}$ & $\Delta V, \%$ \\
\hline Air & 0.1 & $373-393$ & $10-12$ & \multirow{2}{*}{850} & 87 \\
\hline Water & 0.005 & $353-363$ & $5-7$ & 780 & 73 \\
\hline Water + butanol 10\% & 0.1 & $363-373$ & $20-30$ & 930 & 84 \\
\hline Butanol & 0.1 & $363-373$ & $10-15$ & 1020 & 93 \\
\hline Butanol & 0.1 & $363-373$ & $2-3$ & 1040 & 96 \\
\hline Butanol + toluene 5-10\% & 0.1 & $378-388$ & $1-2$ & 1040 & 96 \\
\hline
\end{tabular}

The obtained results of the research concerning the gas phase release from FSP allowed determining the optimal technological parameters of the process by applying different mediums (Table).

The conducted researches also allow to propose a constructive design of the degazation process. To ensure the high efficiency and productivity of the process via the continuous scheme a cylindrical apparatus has been proposed, the specificity of which is a system of continuous unloading of the degassed FPS. The mentioned system consists of a screw conveyor and scraper providing the gathering and delivery to the screw of the degassed FPS.
In order to obtain a compacted FPS of the required quality the height of the apparatus should be sufficient to provide the necessary time for FPS staying in the reactor. The time, as was shown by the research relating to the regularities of FPS degazation in butanol solutions, is 1-1.5 min depending on the technological characteristics of the secondary raw material.

Obviously, the main parameter for calculating the geometric dimensions of the apparatus is the sedimentation velocity of the particle during the degazation. Using the proposed calculation method and substituting Eq. (4) into (3) we obtain the equation for calculating the sedimentation velocity of the FPS particle of irregular shape: 


$$
\omega_{\mathrm{S}}=\frac{\operatorname{Re} \mu_{\mathrm{m}}}{\rho_{\mathrm{m}}\left(1.24 \sqrt[3]{\frac{\mathrm{m}}{\rho}}\right)}
$$

Since the density of the FPS is changed during the degassing process, it is necessary to determine a number of assumptions allowing to calculate the sedimentation start time and the velocity at which the particle of the degassed FPS precipitates in the butanol solution. A separate FPS particle begins to precipitate when achieving the density of the butanol solution heated to the required temperature. The butanol density at $363 \mathrm{~K}$ is $758 \mathrm{~kg} / \mathrm{m}^{3}$, foam polystyrene (initial apparent density is $20 \mathrm{~kg} / \mathrm{m}^{3}$ ) reaches this density after $40 \mathrm{~s}$. At the same time, the sedimentation velocity of PS particle with an initial volume of about $1 \mathrm{~cm}^{3}$ is $0.087 \mathrm{~m} / \mathrm{s}$. Thus, the height of the working part of the reactor can be considered as the track passed by the particle for $50 \mathrm{~s}$ (the time of reaching the maximum density ( $90 \mathrm{~s}$ ) minus the start time of the sedimentation $(40 \mathrm{~s})$ ). In this case the apparatus height will be $4.35 \mathrm{~m}$.

When using the apparatus of the proposed design its productivity will depend on the area of contact FPS with a butanol solution, i.e., on the apparatus cross section, and can be calculated by Eq. (8):

$$
F=\frac{V}{\omega_{s}^{\prime}}
$$

where $V$ is a volumetric flow rate of granulated foam polystyrene, $\mathrm{m}^{3} / \mathrm{s} ; \omega^{\prime}{ }_{S}$ is an average calculated sedimentation velocity, $\omega^{\prime}{ }_{S}=0.5 \omega_{S}$.

For example, with the apparatus productivity at an initial FPS of $10 \mathrm{~m}^{3} / \mathrm{h}$, the cross-sectional area of the apparatus will be $0.056 \mathrm{~m}^{2}$, which corresponds to the diameter of $0.134 \mathrm{~m}$.

Thus, the proposed design of the apparatus can be applied for the process of degassing. The subsequent improvement of the apparatus design can be achieved by reducing the geometric dimensions, in particular, by reducing its height. This can be achieved by the increasing of hydraulic resistance acting on the settling particle as a result of the counter current of the solution in the direction the particle sedimentation. It will make possible to decrease the velocity of its sedimentation and thus reduce the height of the device.

\section{Conclusions}

Based on this research it was determined that the optimum medium for the degassing process of secondary FPS are the butanol mediums, in which high compaction degree (at the level of 94-97\%) can be achieved, with high velocity. It makes the proposed technology of secondary FPS utilization attractive from an economic standpoint.

\section{Acknowledgements}

The work was carried out within the framework of the project Physico-chemical fundamentals of the synthesis and modification of selective sorption polymer inorganic (nano) composite materials (state registration number 0118U000263).

\section{References}

[1] Al-Homoud M.S.: Building and Environment, 2005, 40, 353. https://doi.org/10.1016/j.buildenv.2004.05.013

[2] Aditya L., Mahlia T., Rismanchi B. et al.: Renew. Sustain. Energ. Rev., 2017, 73, 1352. https://doi.org/10.1016/j.rser.2017.02.034 [3] Lickly T., Lehr K., Welsh G.: Food Chem. Toxicol., 1995, 33, 475. https://doi.org/10.1016/0278-6915(95)00009-Q [4] Ozturk U., Anlas G.: Mater. Design, 2011, 32, 773. https://doi.org/10.1016/j.matdes.2010.07.025

[5] Di Landro L., Sala G., Olivieri D.: Polym. Test., 2002, 21, 217. https://doi.org/10.1016/S0142-9418(01)00073-3

[6] Sikora J., Gerlach H., Levytskyi V., Moravskyi V.: J. Polym. Eng., 2013, 33, 501. https://doi.org/10.1515/polyeng-2013-0006

[7] Kan A., Demirboğa R.: J. Mater. Process. Techn., 2009, 209, 2994. https://doi.org/10.1016/j.jmatprotec.2008.07.017

[8] Levytskyj V., Laruk Yu., Huminetsky T., Sikora J.: Chem. Chem. Technol., 2015, 2, 199. https://doi.org/10.23939/chcht09.02.199 [9] Moravskyi V., Dziaman I., Suberliak S. et al.: East.-Eur. J. Enterpr. Techn., 2017, 4, 50. https://doi.org/10.15587/17294061.2017.108462

[10] Moravskyi V., Dziaman I., Suberliak S. et al.: $7^{\text {th }}$ Int. Conf. on Nanomaterials: Applications and Properties, Ukraine, Zatoka 2017, 03NNSA18. 10.1109/NAP.2017.8190265

[11] Moravskyi V., Kucherenko A., Kuznetsova M. et al.: East.-Eur. J. Enterpr. Techn.., 2018, 3, 40. https://doi.org/10.15587/17294061.2018.131446

[12] Kasatkin A.: Osnovnye Protsessy i Apparaty Khimicheskoy Tekhnologii. Goskhimizdat, Moskva 1961.

[13] Levytskyi V., Katruk D., Shybanova A. et al:: Mater. Sci., 2017, 52, 559. https://doi.org/10.1007/s11003-017-9990-0

[14] Levyts'kyi V., Katruk D., Kochubei V. et al.: Mater. Sci., 2017, 53, 385. https://doi.org/10.1007/s11003-017-0086-7

Received: November 30, 2018 / Revised: December 03, 2018 / Accepted: March 28, 2019

\section{ФІЗИКО-ХІМІЧНІ ТА ТЕХНОЛОГІЧНІ ЗАКОНОМІРНОСТІ ДЕГАЗАЦІЇ ПІНОПОЛІСТИРОЛУ В РІДКОМУ СЕРЕДОВИЩІ}

\begin{abstract}
Анотація. Виявлені закономірності процесу ущільнення пінополістирольних пластиків в рідинних середовищах, встановлено вплив природи середовища, температури $i$ технологічних характеристик пінополістиролу (уявна густина, ступінь подрібнення) на кінетику вивільнення газової фази в умовах сегментальної рухливості полістиролу. Запропонована конструкиія $і$ методику розрахунку реактора для проведення процесу дегазаиї пінополістиролу за безперервною схемою.
\end{abstract}

Ключові слова: пінополістирол, бутанол, дегазація, утилізація, вторинне використання. 